\title{
Butyrylcholinesterase $\mathrm{K}$ variant is genetically associated with late onset Alzheimer's disease in Northern Ireland
}

S P McIlroy, V L S Crawford, K B Dynan, B M McGleenon, M D Vahidassr, J T Lawson, A P Passmore
Department of

Geriatric Medicine,

The Queen's

University of Belfast,

Whitla Medical

Building, 97 Lisburn

Road, Belfast

BT9 7BL,

Northern Ireland

S P McIlroy

V L S Crawford

K B Dynan

B M McGleenon

M D Vahidassr

A P Passmore

Department of Radiology, The Belfast City Hospital, 97

Lisburn Road, Belfast BT9 7 AB, Northern Ireland

J T Lawson

Correspondence to: Dr McIlroy

Revised version received 20 October 1999

Accepted for publication

16 November 1999

\begin{abstract}
Alzheimer's disease (AD) is a progressive neurodegenerative disorder that has been associated, sometimes controversially, with polymorphisms in a number of genes. Recently the butyrylcholinesterase $K$ variant (BCHE K) allele has been shown to act in synergy with the apolipoprotein $E$ \&4 (APOE \&4) allele to promote risk for AD. Most subsequent replicative studies have been unable to confirm these findings. We have conducted a case-control association study using a clinically well defined group of late onset $A D$ patients $(n=175)$ and age and sex matched control subjects $(n=187)$ from the relatively genetically homogeneous Northern Ireland population to test this association. The BCHE genotypes of patients were found to be significantly different from controls $\left(\chi^{2}=23.68, \mathrm{df}=2, \mathrm{p}<<0.001\right)$. The frequency of the $K$ variant allele was also found to differ significantly in cases compared to controls $\left(\chi^{2}=16.39, \mathrm{df}=1, \mathrm{p}<<0.001\right)$ leading to an increased risk of $A D$ in subjects with this allele (OR=3.50, 95\% CI 2.20-6.07). This risk increased in subjects 75 years and older $(\mathrm{OR}=5.50,95 \%$ CI $2.56-11.87)$. At the same time the APOE $\varepsilon 4$ associated risk was found to decrease from $6.70(95 \%$ CI 2.40-19.04) in 65-74 year olds to 3.05 (95\% CI 1.34-6.95) in those subjects 75 years and older. However, we detected no evidence of synergy between BCHE $K$ and APOE \&4. The results from this study suggest that possession of the BCHE $\mathrm{K}$ allele constitutes a significant risk for $\mathrm{AD}$ in the Northern Ireland population and, furthermore, this risk increases with increasing age.

(F Med Genet 2000;37:182-185)
\end{abstract}

Keywords: Alzheimer's disease; BCHE K; APOE

Alzheimer's disease (AD) is a progressive neurodegenerative disorder, the incidence of which increases sharply in members of the population aged over 65 years. ${ }^{1}$ It is characterised by the extracellular accumulation of $\beta$-amyloid $(A \beta)$ peptide in the form of amyloid plaques in the brains of affected subjects. ${ }^{2}$

Although it is clear that a significant proportion of $\mathrm{AD}$ has a genetic basis, ${ }^{3} \mathrm{APOE}$ is the only genetic factor that has been consistently implicated in non-familial late onset disease. However, the possession of the APOE4 allele is neither necessary nor sufficient for disease initiation/progression. ${ }^{4}$ This fact has prompted a search for other genetic factors that may confer susceptibility to AD.

One of the candidates that has been identified to date is the $\mathrm{K}$ variant of butyrylcholinesterase (BCHE). ${ }^{5}$ These authors reported that the BCHE $\mathrm{K}$ variant acted in synergy with APOE4 to increase the risk for AD, especially in subjects older than 75 years. This enzyme is an attractive candidate for involvement in $\mathrm{AD}$ as it has been hypothesised to participate in the transformation of $A \beta$ from an initially benign form to an eventually malignant form associated with neuritic tissue degeneration and clinical dementia. ${ }^{6}$ The activity of this enzyme has been shown to increase with age and be raised in $\mathrm{AD} .^{7}$ In addition, because $\mathrm{BChE}$ blocks aggregation of $A \beta$ less aggressive long fibrils ${ }^{8}$ and possession of the $\mathrm{K}$ variant allele is known to result in a $30 \%$ reduction in serum cholinesterase activity, ${ }^{9}$ the BCHE $\mathrm{K}$ variant becomes even more attractive as a candidate risk factor for $\mathrm{AD}$.

Although the findings of Lehmann et at have been replicated or partially replicated in some studies, ${ }^{1011}$ a majority have failed to find evidence for association either alone or synergistically with APOE. ${ }^{12-16}$ Because the frequencies of the BCHE $\mathrm{K}$ variant differs in various ethnic populations ${ }^{817} 18$ and the activity of the enzyme has been shown to be high in an Irish population, ${ }^{19}$ we decided to test the association of the $K$ variant with $\mathrm{AD}$ in a clinically well defined cohort of AD cases and controls from the relatively genetically homogeneous population in Northern Ireland. ${ }^{20}$

\section{Materials and methods}

SUBJECTS

Ethical approval for this study was obtained from the Research Ethics Committee, The Queen's University of Belfast. Informed written consent was obtained from patients/carers and controls before collection of blood samples. Patients' blood samples were obtained through The Memory Clinic, Belfast City Hospital and referral from the Alzheimer's Disease Society, Northern Ireland. Control blood samples were obtained from nondemented healthy spouses and volunteers from retirement clubs throughout Northern Ireland. All patients and controls were white and ascertained to have at least parents and grandparents born in Northern Ireland to ensure ethnicity. Any patient with a family history of 
dementia (greater than one first degree relative with any form of dementia) was excluded from the analysis. Diagnosis of probable AD was arrived at using the DSM IV (1994) and NINCDS-ADRDA criteria. ${ }^{21}$ Where possible, a CT scan was performed to aid diagnosis.

Age, sex, and ethnically matched volunteers were recruited as control subjects. Assessment of controls included a full medical history and a physical examination. Using the same criteria as was used for the AD patients, a comprehensive family history was taken to exclude those with a history of dementia. Cognitive function was assessed using Mini Mental State Examination $\left(\mathrm{MMSE}^{22}\right)$. A full blood screen was performed as for the patient group.

The patient group consisted of 62 males and 113 females with a mean age of 77.7 years (SD 5.94, range 67-94 years). Controls consisted of 58 males and 129 females with a mean age of 77.1 years (SD 6.04, range 67-96 years).

GENOTYPING OF THE BCHE AND APOE GENES Genomic DNA was extracted from peripheral blood leucocytes by the "salting out" method. ${ }^{23}$ The BCHE $\mathrm{K}$ variant was detected by the amplification created restriction site method essentially as described ${ }^{24}$ and fragments were sized by reference to a $M s p \mathrm{I}$ digested pBR322 sequencing ladder. APOE genotypes were assigned by PCR-RFLP, as previously described. ${ }^{25}$

STATISTICAL ANALYSIS

Genotype and allele frequencies were compared between $\mathrm{AD}$ cases and controls using the $\chi^{2}$ test with Yates's correction. Odds ratios (OR) as estimates of relative risk for disease were calculated and 95\% confidence intervals obtained by Cornfield's approximation. A logistic regression model was used to test for interaction between the $\mathrm{BCHE} \mathrm{K}$ variant and APOE $\varepsilon 4$. In addition, synergy factor analysis (D Lehman personal communication) was also used to test for any synergistic effect of BCHE $\mathrm{K}$ on $\mathrm{APOE} \varepsilon 4$.

\section{Results}

Distribution of genotypes was found to differ significantly in cases compared to control subjects $\left(\chi^{2}=23.68, \mathrm{df}=2, \mathrm{p}<<0.001\right)$ (table 1 ). The distribution of the genotypes in the control group did not differ from that predicted by Hardy-Weinberg equilibrium; however, the distribution of the genotypes in the cases differed from Hardy-Weinberg. This was not the result of technical error as controls were included in each experiment and in other analyses performed by this group, including APOE in this study, the distribution of genotypes in cases and controls did not differ from that predicted by Hardy-Weinberg equilibrium. ${ }^{2627}$

The distribution of BCHE genotypes in cases aged 65 to 74 differed significantly from the distribution in those aged 75 or greater $\left(\chi^{2}=10.85, \mathrm{df}=2, \mathrm{p}=0.004\right)$, whereas the genotype distribution in controls did not differ between these age groups $\left(\chi^{2}=2.74, \mathrm{df}=2\right.$, $\mathrm{p}=0.25$ ) (table 2). Furthermore, while the dif-
Table 1 Overall distribution of BCHE genotypes

\begin{tabular}{|c|c|c|c|c|}
\hline & \multicolumn{2}{|c|}{ Cases } & \multicolumn{2}{|c|}{ Controls } \\
\hline & No & $\%$ & $\mathrm{No}$ & $\%$ \\
\hline $\mathrm{NN}$ & 84 & 48.0 & 136 & 72.7 \\
\hline $\mathrm{NK}$ & 88 & 50.3 & 48 & 25.7 \\
\hline KK & 3 & 1.7 & 3 & 1.6 \\
\hline
\end{tabular}

$\chi^{2}=23.68, \mathrm{df}=2, \mathrm{p}<<0.001$

Table 2 Distribution of BCHE genotypes in subjects aged between 65 and 74 years and 75 years and older

\begin{tabular}{|c|c|c|c|c|c|c|c|c|}
\hline & \multicolumn{4}{|c|}{$\geqslant 65-74$ years $^{*}$} & \multicolumn{4}{|c|}{$\geqslant 75$ yearst } \\
\hline & \multicolumn{2}{|c|}{ Cases } & \multicolumn{2}{|c|}{ Controls } & \multicolumn{2}{|c|}{ Cases } & \multicolumn{2}{|c|}{ Controls } \\
\hline & No & $\%$ & No & $\%$ & No & $\%$ & No & $\%$ \\
\hline $\mathrm{NN}$ & 38 & 65.5 & 54 & 68.4 & 46 & 39.3 & 82 & 75.9 \\
\hline NK & 19 & 32.8 & 25 & 31.6 & 69 & 59.0 & 23 & 21.3 \\
\hline KK & 1 & 1.7 & 0 & 0 & 2 & 1.7 & 3 & 2.8 \\
\hline
\end{tabular}

${ }^{\star} \chi^{2}=0.10, \mathrm{df}=2, \mathrm{p}=0.95$.

$+\chi^{2}=33.02, \mathrm{df}=2, \mathrm{p}<<0.001$.

Table 3 Distribution of APOE genotypes in subjects aged between 65 and 74 years and 75 years and older

\begin{tabular}{|c|c|c|c|c|c|c|c|c|}
\hline & \multicolumn{4}{|c|}{$\geqslant 65-74$ years } & \multicolumn{4}{|c|}{$\geqslant 75$ years } \\
\hline & \multicolumn{2}{|c|}{ Cases } & \multicolumn{2}{|c|}{ Controls } & \multicolumn{2}{|c|}{ Cases } & \multicolumn{2}{|c|}{ Controls } \\
\hline & No & $\%$ & No & $\%$ & No & $\%$ & No & $\%$ \\
\hline 23 & 2 & 3.4 & 13 & 16.5 & 16 & 13.7 & 16 & 14.8 \\
\hline 24 & 2 & 3.4 & 1 & 1.3 & 6 & 5.1 & 4 & 3.8 \\
\hline 33 & 21 & 36.2 & 52 & 65.8 & 50 & 42.8 & 66 & 61.1 \\
\hline 34 & 27 & 46.7 & 12 & 15.1 & 33 & 28.2 & 22 & 20.3 \\
\hline 44 & 6 & 10.3 & 1 & 1.3 & 12 & 10.2 & 0 & 0 \\
\hline
\end{tabular}

Difference in genotype distribution between age groups in cases $\chi^{2}=8.40, \mathrm{df}=4, \mathrm{p}=0.08$.

Difference in genotype distribution between age groups in controls $\chi^{2}=1.98, \mathrm{df}=4, \mathrm{p}=0.74$.

ference in the distribution of APOE genotypes in these two age groups approached but did not reach significance in the patient group $\left(\chi^{2}=8.40, \mathrm{df}=4, \mathrm{p}=0.08\right)$, the distribution of the genotypes in controls between the two age groups was almost identical $\left(\chi^{2}=1.98, \mathrm{df}=4\right.$, $\mathrm{p}=0.74)$ (table 3).

The frequency of the $\mathrm{K}$ variant allele was also found to be significantly different in cases when compared to controls $\left(\chi^{2}=16.39, \mathrm{df}=1\right.$, $\mathrm{p}<<0.001)$. Computation of the odds ratio as an estimate of relative risk for disease showed that subjects with the BCHE $\mathrm{K}$ variant allele were 3.50 (95\% CI 2.20-6.07) times more likely to suffer from $\mathrm{AD}$. Division of the cases and controls into two age groups as in the genotypes and stratifying for APOE $\varepsilon 4$ showed that the odds ratio associated with the BCHE $\mathrm{K}$ variant increased from 1.26 (95\% CI NS) in the 65 to 74 year olds (table 4 ) to 5.50 (95\% CI 2.56-11.87) in the group aged 75 years or greater (table 5). At the same time the APOE $\varepsilon 4$ associated odds ratio decreased from 6.70 (95\% CI 2.40-19.04) in the younger group to 3.05 (95\% CI 1.34-6.95) in the older group.

The odds ratio for possession of both risk factors increased from 11.26 (95\% CI 2.4168.91 ) in the under 75 year age group (table 4 ) to 24.35 (95\% CI: 6.67 - 88.87) in those subjects of 75 years and older (table 5). However, although 11 cases compared to three controls possessed both risk factors in the younger age group and 26 cases compared to three controls 
Table 4 Carrier odds ratios in the 65 to 74 year subgroup

\begin{tabular}{lllll}
\hline BCHE K & APOE 4 & Cases & Controls & OR $(95 \%$ CI) \\
\hline- & - & 14 & 43 & Reference \\
- & + & 24 & 11 & $6.70(2.40-19.04)$ \\
+ & - & 9 & 22 & $1.26(\mathrm{NS})$ \\
+ & + & 11 & 3 & 11.26 \\
& & & & $(2.41-68.91)$ \\
\hline
\end{tabular}

\begin{tabular}{|c|c|c|c|c|}
\hline BCHE K & APOE 4 & Cases & Controls & OR $(95 \% C I)$ \\
\hline- & - & 21 & 59 & Reference \\
\hline- & + & 25 & 23 & $3.05(1.34-6.95)$ \\
\hline+ & - & 45 & 23 & $5.50(2.56-11.87)$ \\
\hline+ & + & 26 & 3 & $\begin{array}{l}24.35 \\
(6.67-88.87)\end{array}$ \\
\hline
\end{tabular}

possessed both risk factors in the older age group, we found little evidence of interaction between APOE $\varepsilon 4$ and BCHE $K$ either by logistic regression $\left(\chi^{2}=0.13, \mathrm{df}=1, \mathrm{p}>0.1\right)$ or synergy factor analysis $(\mathrm{z}=0.44, \mathrm{p}>0.1)$.

\section{Discussion}

This case-control association study showed a significant difference between the BCHE genotypes of late onset $\mathrm{AD}$ cases and control subjects. However, in agreement with two other studies, ${ }^{511}$ we noticed that this effect was explained by the difference in the distribution of the genotypes in those subjects of 75 years and older. We also report a near significant difference in the APOE genotypes in AD cases of 65 to 74 years and those patients of 75 years and older. This difference was not reflected in control genotypes.

In agreement with three previous studies, ${ }^{5} 1011$ the frequency of the BCHE K variant allele in this study was significantly higher in cases when compared to control subjects. Two of these ${ }^{511}$ reported an increase in the $\mathrm{OR}$ for $\mathrm{AD}$ when the cases and controls were stratified for age and APOE $\varepsilon 4$. Our results are in agreement in that the $\mathrm{BCHE} \mathrm{K}$ associated $\mathrm{AD}$ risk rises from 1.26 in subjects aged 65 to 74 years to 5.50 in those subjects of age greater than 74 years. These data suggest that the $\mathrm{BCHE} \mathrm{K}$ variant is a significant risk factor for late onset $\mathrm{AD}$ and that this risk rises with increasing age.

Other groups have not been able to find an association between the $\mathrm{BCHE} \mathrm{K}$ variant and late onset $\mathrm{AD}$ in their populations. ${ }^{12-16} \mathrm{~A}$ possible explanation for this may be that the frequency of cholinesterase variants differs in various ethnic populations, ${ }^{817} 18$ which may lead to spurious results owing to the effects of hidden population admixtures. Another factor that could explain this discrepancy is that the BCHE K variant may be in linkage disequilibrium with an as yet unidentified AD susceptibility gene in some populations but not in others.

This study also reports a reduction in the APOE $\varepsilon 4$ associated risk for AD with increasing age. This is also in agreement with other published observations. Duara et $a l^{28}$ reported that the APOE \&4 frequency declined significantly with increasing age and Blacker et a ${ }^{29}$ observed that the APOE $\varepsilon 4$ allele exerts its maximum effect before the age of 70 years. In addition, Scacchi et $a l^{30}$ reported no difference between case and control frequencies of subjects older than 80 years even though the APOE $\varepsilon 4$ associated risk was present in subjects less than 80 years of age. These reports indicate that it is important to identify a factor that may influence $\mathrm{AD}$ risk in the very old and the results of this study suggest that the $\mathrm{BCHE}$ $\mathrm{K}$ variant is a reasonable candidate.

In conclusion we report that the BCHE K variant is a significant risk factor for late onset $\mathrm{AD}$ in the Northern Ireland population. The odds ratio associated with this risk increases in people older than 75 years; however, we were unable to show any synergy with APOE $\varepsilon 4$.

The authors wish to acknowledge the Department of Health and Social Services (DHSS) for their support of MDV in this research. We thank the DHSS and Ulster Garden Villages for their support of BMMcG. We also thank the Alzheimer's Disease Society of Northern Ireland for their support.

1 Smith MA. Alzheimer disease. Int Rev Neurobiol 1998;42:154.

2 Khachaturian Z. Diagnosis of Alzheimer's disease. Arch Neurol 1985;42:1097-105.

3 Tanzi RE, Gaston S, Bush A, et al. Genetic heterogeneity of gene defects responsible for familial Alzheimer's disease. Genetics 1994;91:255-63

4 Strittmatter WJ, Roses AD. Apolipoprotein E and Alzheimer disease. Proc Natl Acad Sci USA 1995;92:4725-7.

5 Lehmann DJ, Johnsin C, Smith AD. Synergy between the genes for butyrylcholinesterase $\mathrm{K}$ variant and apolipoprotein E4 in late-onset confirmed Alzheimer's disease. Hum Mol Genet 1997;6:1933-6.

6 Guillozer AL, Smiley JF, Mash DC, Mesulam MM. Butyrylcholinesterase in the life cycle of amyloid plaques. Ann Neurol 1997; 42 : in the

Ann Neurol 1997;42:909-18.
7 Perry EK. The cholinergenic system in old age and Perry EK. The cholinergenic system in

8 Barber K, Mesulam M, Kraft G, Klein W. Butyrylcholinesterase (BchE) alters the aggregation state of $A \beta$ amyloid. Soc Neurosci Abstr 1996;22:1172.

9 Bartels CF, Jensen FS, Lockridge O, et al. DNA mutation associated with the human butyrylcholinesterase K-variant and its linkage to the atypical variant mutation and other polymorphic sites. Am f Hum Genet 1992;50:1086-103.

10 Sandbrink R, Gasperina A, Zerfass R, et al. Butyrylcholinesterase $\mathrm{K}$ variant (BCHE $\mathrm{K}$ ): association with lateonset Alzheimer's disease. Neurobiol Aging 1998;19:S69A.

11 Wiebusch H, Poirier J, Sévigny P, Schappert K. Further evidence for a synergistic association between APOE $\varepsilon 4$ and BCHE-K in confirmed Alzheimer's disease. Hum Genet 1999;104:158-63.

12 Brindle N, Song Y, Rogaeva E, et al. Analysis of the butyrylcholinesterase gene and nearby chromosome 3 markers in cholinesterase gene and nearby chromosome 3 marke

13 Crawford F, Fallin D, Suo A, et al. The butyrylcholinesterase gene is neither independently nor synergistically associated with late-onset $\mathrm{AD}$ in clinic- and community-based populations. Neurosci Lett 1998;249:115-18.

14 Helbeque N, Cottel D, Hermant X, Guez D, Amouyel P. The butyrylcholinesterase $\mathrm{K}$ variant is not associated with Alzheimer's disease. Alz Rep 1998;1:309-13.

15 Hiltunen M, Mannermaa A, Helisalmi S, et al. Butyrylcholinesterase $\mathrm{K}$ variant and apolipoprotein $\mathrm{E} 4$ genes do not act in synergy in Finnish late-onset Alzheimer's disease patients. Neurosci Lett 1998;250:68-71.

16 Kehoe PG, Williams H, Holmans P, et al. The butyrylcholinesterase $K$ variant and susceptibility to Alzheimer's disease. F Med Genet 1998;35:1034-5.

17 Evans RT, Wardell J. On the identification and frequency of the $\mathrm{J}$ and $\mathrm{K}$ cholinesterase phenotypes in a Caucasian the J and K cholinesterase phenotypes

population. $\mathcal{F}$ Med Genet 1984;21:99-102.
18 Whittaker M, Britten JJ. Plasma cholinesterase variants. Family studies of the E1k gene. Hum Hered 1985;35:364-8. 19 Hosseini J, Firuzian F, Feely J. Ethnic differences in the freHosseini J, Firuzian F, Feely J. Ethnic differences in the fre-
quency distribution of serum cholinesterase activity. Ir $\mathcal{f}$ Med Sci 1997;166:10-20.

20 Zchocke J, Mallory JP, Eiken HG, Nevin NC. Phenylketonuria and the peoples of Northern Ireland. Hum Genet 1997;100:189-94

21 McKhann G, Drachman D, Folstein M, Katzman R, Price D, Stadlan EM. Clinical diagnosis of Alzheimer's disease: report of the NINCDS-ADRDA work group under the auspices of the Department of Health and Human Services task force of Alzheimer's disease. Neurology 1984;34:939-44.

22 Folstein MF, Folstein SE, McHugh PR. Mini-Mental State. A practical method for grading the cognitive state of patients for the clinician. I Psychiatr Res 1975;12:189-98.

patients for the clinician. F Psychiatr Res $1975 ; 12: 189-98$.
23 Miller SA, Dykes DD, Polesky HF. A simple salting out procedure for extracting DNA from human nucleated cells. Nucleic Acids Res 1988;13:1215. 
24 Jensen FS, Nielsen LR, Schwartz M. Detection of the plasma cholinesterase K variant by PCR using an amplifica

25 Crooks R, Hardy J, Duff K. Single-day apolipoprotein E genotyping. F Neurosci Methods 1994;53:125-7.

26 McIlroy SP, Dynan KB, McGleenon BM, Lawson JT, Passmore AP. Cathepsin D gene exon 2 polymorphism and sporadic Alzheimer's disease. Neurosci Lett 1999; 273:140-1.

27 Mcllroy SP, Vahidassr MD, Savage DA, Patterson CC, Lawson JT, Passmore AP. Risk of Alzheimer's disease is associated with a very low density lipoprotein receptor
genotype in Northern Ireland. Am $\mathcal{F}$ Med Genet 1999;88: $140-4$.
28 Duara R, Barker WW, Lopez-Alberola R, et al. Alzheimer's disease: interaction of apolipoprotein $\mathrm{E}$ genotype, family history of dementia, gender, education, ethnicity and age of onset. Neurology 1996;46:1575-9.

29 Blacker D, Haines JL, Rodes L, et al. APOE-4 and age of onset of Alzheimer's disease: the NIMH genetics initiative. Neurology 1997;48:139-47.

30 Scacchi R, De Bernardini L, Mantuano E, Donini LM, Vilardo T, Corbo RM. Apolipoprotein E (APOE) allele frequencies in late onset sporadic Alzheimer's disease (AD), mixed dementia and vascular dementia: lack of association of epsilon 4 allele with $\mathrm{AD}$ in Italian octogenarian patients. Neurosci Lett 1995;210:231-4. 